\title{
Clinically Diagnosed Guillain-Barre Syndrome in Pregnancy: Case Report and Review of Literature
}

\author{
Afolabi Korede Koledade1, Adekunle 0. Oguntayo1, Sani A. Abubakar², \\ Godfrey K. Katung1, Sunday Oladapo Shittu1 \\ ${ }^{1}$ Obstetrics and Gynaecology Department, Ahmadu Bello University Teaching Hospital, Zaria, Nigeria \\ ${ }^{2}$ Neurology Unit, Internal Medicine Department, Ahmadu Bello University Teaching Hospital, Zaria, Nigeria \\ Email: akdade@yahoo.com
}

Received 10 June 2014; revised 9 July 2014; accepted 5 August 2014

Copyright (C) 2014 by authors and Scientific Research Publishing Inc.

This work is licensed under the Creative Commons Attribution International License (CC BY). http://creativecommons.org/licenses/by/4.0/ (c) (i) Open Access

\section{Abstract}

Background: Guillain-Barre syndrome (GBS) is an autoimmune disorder characterized by a heterogeneous group of pathological and clinical entities. It is associated with ascending areflexic paralysis, some autonomic dysfunction and respiratory failure in severe cases and ultimately death if not promptly diagnosed and treated. It may be preceded by an antecedent event in about two-third of cases. This could be an upper respiratory tract infection, viral illness, recent history of vaccination, pregnancy, cancer or even trauma. The condition is exceedingly rare in pregnancy and only few cases have been reported in literature. Case Report: This is a case of a 28-year-old Gravida 3, Para $1^{+1}$ and Estimated Gestational Age of 30 weeks and 4 days. There was a history of upper respiratory tract infection eight weeks prior to presentation which spontaneously resolved. On examination, she was a young woman, anxious, weak, afebrile, not pale, the neck could not hold the head upright and there was bilateral non tender pitting pedal oedema extending to her midshin. There were no cranial nerve deficits and no sign of meningeal irritation. There were normal muscle bulk with global hypotonia and flaccid quadriparesis, Power was $3 / 5$. The proximal groups of muscles were more affected than the distal parts. Reflexes were diminished globally with plantar flexor response. She had immunoglobulin as treatment. Conclusion: In a low resource setting like ours it is important to have a high index of suspicion of GBS when an apparently healthy gravid woman presents with progressive weakness of the limbs.

\section{Keywords}

Guillain-Barre Syndrome, Pregnancy, Immunoglobulin, Plasmapheresis 


\section{Introduction}

Guillain-Barre syndrome (GBS) also known as Acute Inflammatory Demyelinating Polyneuropathy (AIDP) is an autoimmune disorder characterised by a heterogeneous group of pathological and clinical entities. It is associated with ascending areflexic paralysis, some autonomic dysfunction and respiratory failure in severe cases and ultimately death if not promptly diagnosed and treated. It was first described by Landry in 1859 [1] and then by Gullian, Barre and Strohl in 1916 [1] in two French soldiers with motor weakness, who were flexia and albuminocytological dissociation. They introduced the concept of "albuminocytologic dissociation" in the cerebrospinal fluid as a laboratory marker to distinguish this disorder from other neuropathies as well as from poliomyelitis. GBS is now recognised to be a diverse disorder. There are several patterns of disorders which are based on the mode fibre injury which could be demyelinating or axonal. Based on the nerve fibres involved it could be motor-sensory or motor-cranial pattern [2].

The mode of presentation is usually that of motor dysfunction in almost all cases characterised by symmetrical limb weakness mostly affecting the proximal group of muscles. There is also affectation and weakness of neck muscles; respiratory muscle weakness and difficulty in swallowing; absent reflexes, pain and autonomic dysfunction. Facial dysdiplegia occurs in about $50 \%$ of cases with extraoccular muscle involvement in some. Other symptoms include transient urinary retention in $10 \%$ to $20 \%$ of cases, pains of muscle aches in $30 \%$ to $50 \%$ and objective sensory loss. Some variants of Gullain-Barre syndrome include acute motor-sensory axonal neuropathy. They have severe fulminant paralysis, sensory loss and incomplete recovery. Those with acute motor axonal neuropathy (Chinese paralytic syndrome) present with acute weakness or paralysis without sensory loss and are closely associated with campylobacter infection. They tend to recover rapidly. The third one is Fisher syndrome. It presents with opthalmoplegia, ataxia and areflexia, facial nerves may be involved in addition to ocular motor nerves, and limb weakness is infrequent. In Bickerstaff brainstem encephalitis, they usually present with disturbance of consciousness, hyperreflexia, ataxia and opthalmoplagia. Other variants are pharyngealcervical-brachial variant, acute pandysautonomia and sensory Gullain-Barre syndrome [3].

Treatment is usually plasmapheresis or use of immunoglobulin with good response. Due to the high cost of immunoglobulin, some advocate the use of plasmapheresis alone with good results [4]. In cases where patients can afford the cost, immunoglobulin has lesser risks and yields good outcomes.

Though data in our environment on the prevalence of this disease are sparse, it is reported to occur in about 1 to 3 per 100,000 individuals based on population surveys worldwide [1]. A study in Kano, Nigeria among 98 patients with paraplegia reported an incidence of 9.2\% [5]. It may be preceded by an antecedent event in about two-third of cases. This could be an upper respiratory tract infection, viral illness, recent history of vaccination, pregnancy, cancer or even trauma. The condition is exceedingly rare in pregnancy and only few cases have been reported in literature [4].

We present a case of AIDP in pregnancy managed with High dose immunoglobulin in a low resource setting.

\section{Case Summary}

This is a case of a 28-year-old Gravida 3, Para $1^{+1}$ with previous history of spontaneous abortion, and Estimated Gestational Age at presentation was thirty weeks and four days. There was a history of upper respiratory tract infection eight weeks prior to presentation which spontaneously resolved. She presented to the emergency unit of our hospital with a two months history of non-productive cough, two day history of lower limb weakness and inability to walk. A day history of lower limb swelling and pain including inability to hold her neck unsupported with difficulty in swallowing. She suddenly slumped while coming out of the bathroom after noticing weakness in her legs. While on admission, she developed difficulty in swallowing solid feeds.

On examination, she was a young woman, anxious, weak, afebrile, not pale, anicteric, acyanosed, the neck could not hold the head upright and there was bilateral non tender pitting pedal oedema extending to her mid-shin. There were no enlarged lymph nodes. Respiratory rate was 16 cycles per minute with clinically clear lung fields bilaterally. The pulse rate was 110 beats per minute and blood pressure was normal (120/70 mmHg). Her abdomen was uniformly enlarged and fundal height was compatible with her estimated gestational age. Foetalheart tone was heard and was regular. There were no cranial nerve deficits and no sign of meningeal irritation. There were normal muscle bulk with global hypotonia and flaccid quadriparesis, Power was Medical Research Council (MRC) grading of 3/5. The proximal groups of muscles were more affected than the distal parts. Reflexes were diminished globally with plantar flexor response. A working diagnosis of AIDP in pregnancy was 
made and laboratory investigation requested.

Hematocrit was $30.5 \%$, Total white blood cell count of $7.4 \times 10^{9} /$, granulocytes of $72.1 \%$, lymphocytes $22.9 \%$, eosinophil of $5.0 \%$. Urea and Electrolytes were normal. Retroviral screen was negative. A lower limb Compression Doppler ultrasound was done which ruled out deep venous thrombosis of the lower limbs. The abdominal ultrasound revealed a viable singleton 3rd trimester cyesis. Chest X-ray was normal. Lumbar puncture and Nerve conduction studies/electromyography could not be done because of advanced cyesis. On the second day of admission, 10 grams of Immunoglobulin was administered to her as a stat dose. She was already on antibiotics and intravenous fluids.

By the third day on admission, power had improved to $4 / 5$ globally and was progressively able to hold the neck upright. Also she was able to swallow food easily. She was observed for eleven more days on the ward when she could walk unsupported then discharged to ante-natal and neurology clinics for follow-up.

She went into spontaneous labour at term and was delivered of a live healthy baby by emergency caesarean section on account of poor progress in labour. Mother and baby are fine.

\section{Discussion}

AIDP is an auto-immune mediated disorder that is usually preceded by four to six weeks history of a respiratory tract infection or gastrointestinal tract infection. Common organisms associated with this condition include Epstein Bar virus, Cytomegalovirus especially in pregnant patients, Mycoplasma pneumonia among others [6]. This implicates antibody reaction to viral and bacterial antigens leading to immune-mediated complexes that attack the myelin and sometimes axonal components of peripheral and central nerves. Other risk factors for the disorder include trauma, tumor as well as pregnancy. This patient was pregnant and had a history of respiratory tract infection within the eight weeks prior to presentation and she presented in the third trimester. It is noteworthy that AIDP can occur in any trimester of pregnancy but is commoner in the third trimester and postpartum period. This is explained by the fact that in pregnancy, there is a shift from cellular to humoral immunity as a result of increased production of interleukin 10. Following delivery, there is a reversal leading to worsening of symptoms [4]. The mortality associated with AIDP in pregnancy is higher than in the general population estimated at $7 \%$ as against that of $<5 \%$ in the general population [7]. The management is mainly supportive including ICU care for patients with respiratory failure. Immunomodulation with immunoglobulin and plasmapheresis have been widely used with good results. The consensus on the optimal use of high dose immunoglobulin is still controversial, despite its widespread application in immune mediated neuropathies [8]. The patient had a high dose of immunoglobulin with satisfactory recovery.

In a similar report of acute inflammatory demyelinating polyradiculoneuropathy in early pregnancy by Zeeman, the condition was treated with immunosuppression and plasmapheresis. The pregnancy was terminated at 18 weeks of gestation however the patient was still in remission a year post abortion. The submission was that Guillain-Barre syndrome must be considered in new onset peripheral neuropathy in pregnancy. It was noted that relapse occurs three times more often during pregnancy and plasmapheresis was the recommended treatment [2].

\section{Conclusion}

In a low resource setting like ours it is important to have a high index of suspicion of GBS when an apparently healthy gravid woman presents with progressive weakness of the limbs. This is to enable early intervention which may not be easily accessible or even affordable before respiratory muscles get involved as intensive care units may not be optimal. In the case reported only a dose of immunoglobulin was sufficient to reverse the pathology though it was expensive and difficult to access.

\section{References}

[1] Seneviratne, U. (2000) Guillain-Barre Syndrome. Postgraduate Medical Journal, 76, 774-782. http://pmj.bmj.com/content/76/902/774.full

[2] Zeeman, G.G. (2001) A Case of Acute Inflammatory Demyelinating Polyradiculoneuropathy in Early Pregnancy. American Journal of Perinatology, 18, 213-215.

[3] Soliven, B. and Roos, R.P. (2013) Neurology Medlink. http://www.medlink.com/medlinkcontent.asp

[4] Vasudev, R. and Raina, T.R. (2014) A Rare Case of Guillain-Barré Syndrome in Pregnancy Treated with Plasma Ex- 
change. Asian Journal of Transfusion Science, 8, 59-60.

http://www.ajts.org/article.asp?issn=0973-6247;year=2014; volume=8;issue=1;spage=59;epage=60; aulast=Vasudev

[5] Owolabi, L.F., Ibrahim A., Samaila A.A. (2011) Profile and Outcome of Non-Traumatic Paraplegia in Kano, Northwestern Nigeria. Annals of African Medicine, 10, 86-90.

http://www.annalsafrmed.org/article.asp?issn=1596-3519; year=2011; volume=10;issue=2; spage=86; epage=90; aulast= Owolabi

[6] Zafar, M.S.H., Naqash, M.M., Bhat, T.A. and Malik, G.M. (2013) Guillain-Barré Syndrome in Pregnancy: An Unusual Case. Journal of Family Medicine and Primary Care, 2, 90-91.

http://www.jfmpc.com/article.asp?issn=2249-4863; year=2013; volume=2;issue=1; spage=90; epage=91; aulast=Zafar

[7] Furara, S., Maw, M., Khan, F. and Powell, K. (2008) Weakness in Pregnancy-Expect the Unexpected. Obstetric Medicine, 1, 99-101. http://dx.doi.org/10.1258/om.2008.080011

[8] Elovaara, I., Apostolski, S., Van Doorn, P., Gilhus, N.E., Hietaharju, A., Honkaniemi, J., et al. (2008) EFNS Guidelines for the Use of Intravenous Immunoglobulin in Treatment of Neurological Diseases: EFNS Task Force on the Use of Intravenous Immunoglobulin in Treatment of Neurological Diseases. European Journal of Neurology, 15, 893-908. http://www.ncbi.nlm.nih.gov/pubmed/18796075 
Scientific Research Publishing (SCIRP) is one of the largest Open Access journal publishers. It is currently publishing more than 200 open access, online, peer-reviewed journals covering a wide range of academic disciplines. SCIRP serves the worldwide academic communities and contributes to the progress and application of science with its publication.

Other selected journals from SCIRP are listed as below. Submit your manuscript to us via either submit@scirp.org or Online Submission Portal.
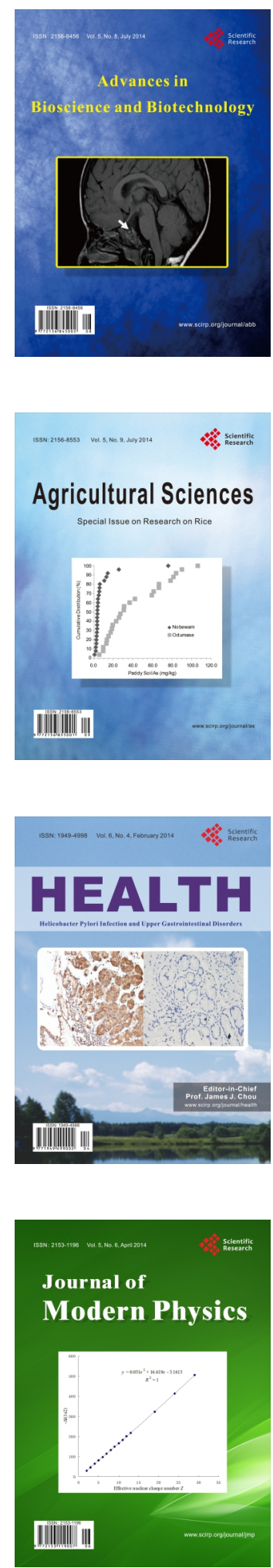
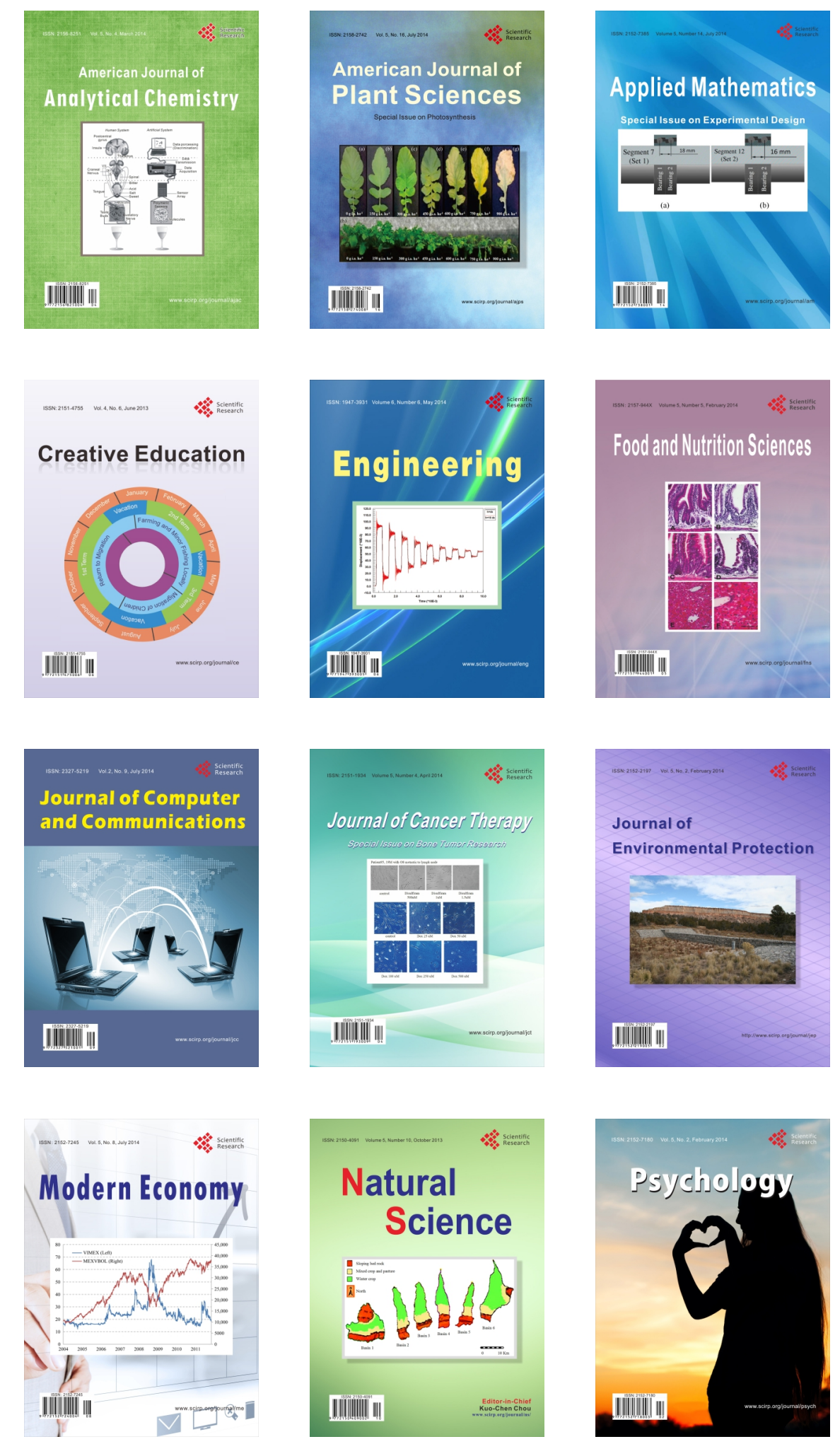